\title{
Prevention of ACL injuries: how, when and who?
}

\author{
Grethe Myklebust $\cdot$ Kathrin Steffen
}

Published online: 13 June 2009

(C) Springer-Verlag 2009

In a comprehensive review presented in this issue, Alentorn-Geli et al. [1] have focused on neuromuscular training programs developed to alter risk factors associated with an ACL injury, and to reduce injury risk in soccer players. The authors conclude that neuromuscular training appears to be effective in reducing ACL injury risk and that lower extremity strength and balance exercises, in combination with core and trunk control seem to be necessary components of a successful ACL injury prevention program.

Since Alentorn-Geli et al. finished their thorough review, a new study has been published which reinforces their message. In a randomized controlled study Soligard et al. [8], the objective was to examine the effect of a comprehensive warm-up program designed to reduce the risk of lower extremity injuries among female soccer players. Approximately 1,900 players participated in the study. The warm-up program, called "The 11+" includes exercises to improve lower extremity and core strength, awareness and neuromuscular control during static and dynamic movements. After 8 months of training, the intervention group had a significantly lower risk of injuries overall (32\%), of overuse injuries (53\%) and of severe injuries $(45 \%)$ compared with the controls. The " $11+$ " exercises, as in many of the other studies presented in the review, compose a multifaceted program and address many neuromuscular components that are thought to be related to ACL and lower extremity injury risk.

G. Myklebust $(\bowtie) \cdot$ K. Steffen

Oslo Sport Trauma Research Center, Norwegian School

of Sports Sciences, Sognsvn 220, 0806 Oslo, Norway

e-mail: grethe.myklebust@nih.no

K. Steffen

e-mail: kathrin.steffen@nih.no
From these latest investigations, we have conclusive evidence that lower extremity injuries in general $[7,8]$ and ACL injuries in particular $[3,4,6]$ can be prevented by a combination of balance/coordination, strength, plyometric and agility exercises.

\section{How? What type of exercises?}

ACL injury prevention works. However, we still do not know how to optimize injury prevention programs to make them time efficient; which exercises are the "right ones", or the "perfect ones", if such exercises exist at all. Another important challenge is to convince coaches and athletes to use the present knowledge. "Are the exercises really worth doing? It takes $20 \mathrm{~min}$; is it necessary to do this program every training session?" This is only some of the skepticism we hear when we are out in the field. As team PTs and researchers, our hope is to find the minimal-effective dose to reduce the number of ACL injuries effectively: hopefully 2-4 exercises, 5-10 $\mathrm{min}, 2-3$ times a week will be sufficient.

This, to identify the minimal effective dose to reduce ACL injury risk, is a daunting task. To answer questions such as which exercises are key-strength, balance, plyometric or agility, or what minimal combination of exercise types that work in synergy-much work is needed. However, achieving the statistical power needed, it is not possible to use injury as the end-point. Valid intermediate endpoints related to landing and cutting mechanics need to be identified.

Having these methodological challenges in mind, we should probably focus more on the mechanism of injury (MOI) in our search for answers. What happens when the ACL ruptures, is it a "valgus collapse" or loading in the 
sagittal plane? This debate is not the issue here, but a more complete understanding of the mechanism could help us develop more specific prevention programs. In doing so, as recently pointed out by Meeuwisse [5], we also need to address situations that do not end in an ACL injury, the mechanism of no injury (MONI). Contrasting the MOI with the MONI may provide us with important clues.

\section{When to start?}

When giving recommendations in relation to the right age for implementing prevention exercises, most authors suggest that we start as soon as children start participating in organized sports. From a motor learning development aspect, this age (6-12) might be important in relation to develop "good habits" and less vulnerable movement patters, in addition to establish correct playing technique and fair play.

But the youngest age groups are at low risk for injury. Actually, soccer is a safe sport for children. This is the conclusion of a newly published study by Froholdt et al. [2]. The authors examined the risk of injuries in children 616 years old playing organized soccer. They presented injury data as relative injury risk (injury per 1,000 playing hours) and absolute injury risk (total number of injuries to a player or team during a season) and compared the numbers with injury data from elite soccer players. Interestingly, the comparison showed that elite players had an absolute injury risk which was 11 and 30 times higher than girls' ages 13-16 years and 6-12 years, respectively. Therefore, spending time on specific injury prevention programs among the youngest, who perhaps train once or twice a week, is probably neither realistic nor necessary. The results of Froholdt et al. (2) support the notion that we should put most effort into prevention from 12-14 years. However, as mentioned earlier, good warm-up routines and movement patters should be developed from the start.

\section{Who should be targeted?}

Most prevention programs today are made as one-sizefits-all package, to be performed by all athletes. Hopefully, future studies will give more specific knowledge about which type of exercises different sports and different athletes should perform. Further evidence is needed to determine whether a pre-season functional testing, e.g., by a drop-jump or single-leg squat test, can be used to identify athletes with higher risk, e.g., poor knee control.

\section{Take home message}

It is possible to prevent ACL injuries; however, much research is still needed. A better understanding on ACL injury risk factors and mechanisms may optimize current injury prevention programs and consequently result in fewer serious knee injuries and lower costs for the public health system. Nevertheless, while new studies are being done, the existing knowledge needs to be put into practice. Spread the current knowledge, show and convince coaches, athletes and sport federations that ACL prevention is possible. Establish warm-up routines, stop talking about "injury prevention programs" or "special programs", call them "exercises that improve performance, and reduce injuries". This will make it an easier sell!

\section{References}

1. Alentorn-Geli E, Myer G, Silvers H, Samitier G, Romero D, Lázaro-Haro C, Cugat R (2009). Prevention of non-contact anterior cruciate ligament injuries in soccer players. Part 2: a review of prevention programs. Knee Surg Sports Traumatol Arthrosc. doi:10.1007/s00167-009-0823-z

2. Froholdt A, Olsen OE, Bahr R (2009) Low risk of injuries among children playing organized soccer: a prospective cohort study. Am J Sports Med; 17 March (Epub ahead of print)

3. Gilchrist J, Mandelbaum BR, Melancon H, Ryan GW, Silvers HJ, Griffin LY, Watanabe DS, Dick RW, Dvorak J (2008) A randomized controlled trial to prevent noncontact anterior cruciate ligament injury in female collegiate soccer players. Am J Sports Med 36:1476-1483

4. Mandelbaum BR, Silvers HJ, Watanabe DS, Knarr JF, Thomas SD, Griffin LY, Kirkendall DT, Garrett W Jr (2005) Effectiveness of a neuromuscular and proprioceptive training program in preventing anterior cruciate ligament injuries in female athletes: 2-year follow-up. Am J Sports Med 33:1003-1010

5. Meeuwisse WH (2009) What is the mechanism of no injury (MONI)? Clin J Sports Med. 19:1-2

6. Myklebust G, Engebretsen L, Braekken IH, Skjølberg A, Olsen OE, Bahr R (2003) Prevention of anterior cruciate ligament injuries in female team handball players: a prospective intervention study over three seasons. Clin J Sport Med 13:717-718

7. Olsen OE, Myklebust G, Engebretsen L, Holme I, Bahr R (2005) Exercises to prevent lower limb injuries in youth sports: cluster randomised controlled trial. BMJ 330(7489):449-455

8. Soligard T, Myklebust G, Steffen K, Holme I, Silvers H, Bizzini M, Junge A, Dvorak J, Bahr R, Andersen TE (2008) Comprehensive warm-up programme to prevent injuries in young female footballers: cluster randomised controlled trial. BMJ 337:2469. doi:10.1136/bmj.a2469 